\title{
Assessment of Efficiency of Using Clinical Pulmonary Infection Score (CPIS) on Length of Stay (LOS) among Mechanically Ventilated Cases
}

\author{
SARA A.A.M. HEIKAL, M.Sc.*; SALWA ABD ELAZEEM, M.D.*; SAHAR YASSIN, M.D.*; \\ DOA'A A.E. SALEH, M.D.* and LAMIA'A H. MOHAMMED, M.D.** \\ The Departments of Public Health \& Community Medicine* and Critical Care, Kasr El-Aini Hospital**, \\ Faculty of Medicine, Cairo University
}

\begin{abstract}
Background: VAP is pneumonia that develops in a mechanically ventilated patient with a first positive bacterial culture beyond 48 hours after hospital admission or tracheal intubation, whichever occurred first. VAP burden relies on the increase of morbidity, cost, prolonged MV, ICU-Length of Stay (LOS) and hospital-length of stay.

Aim of Study: Improve health outcome of patients on Mechanical Ventilation (MV) through early diagnosis of (VAP), early management with appropriate antibiotics prescription using Clinical Pulmonary Infection Score (CPIS) and to decrease MV days, ICU-Length of Stay (LOS) and hospital-length of stay.
\end{abstract}

Methods: Operational research, quasi-experimental interventional study design. The study was conducted in the in Critical Care Department in the Faculty of Medicine CairoUniversity. The study has 2 phases Phase 1: Recruiting the Control group (40 cases) on MV not using CPIS. Phase 2: Recruiting the Interventional group (40 cases) on MV using CPIS.

Results: The most common organism in control group was Klebsiella $25 \%$ and in intervention group was MRSA $17.5 \%$. The ICU LOS was significantly lower in patients who were followed by CPIS in intervention group.

Conclusion: CPIS considered tool to monitor patient's condition on MV for early modification which in turn reflected on ventilator days and ICU length of stay.

Key Words: Mechanical ventilation $M V$-Ventilator associated pneumonia VAP - Intensive Care Unit ICU Clinical pulmonary infection score CPIS - Acute physiology and chronic health evaluation APACHE - Length of stay LOS.

Correspondence to: Dr. Sara Ahmed A.M. Heikal, The Department of Public Health \& Community Medicine, Faculty of Medicine, Cairo University

\section{Introduction}

VENTILATOR-Associated Pneumonia (VAP): Is a pneumonia where the patient is on mechanical ventilation for $>2$ calendar days ( 24 hours) when all elements of the pneumonia infection criterion were first present together, with day of ventilator placement being day 1 , and the ventilator was in place on the date of event or the day before. If the patient is admitted or transferred into a facility on a ventilator, the day of admission is considered day $1[\mathbf{1 , 2}]$

VAP leads to prolonged LOS, MV days and it remains to be the commonest cause of hospital morbidity and mortality [3]. More over economic impact of VAP is significantly high since ICUs incur an important part of hospital expenses. Therefore, prevention of VAP and early diagnosis of it could reduce the care utilized during hospitalization and decrease resource utilization, LOS and subsequent expenses $[4,5]$.

The major goals of VAP management are early diagnosis, appropriate antibiotics treatment in adequate doses followed by de-escalation based on microbiological culture results and the clinical response of the patient. Empowerment of antibiotic stewardship maintain quality of care through simple and cost-effective way to improve clinical outcomes while minimizing antibiotic side effects and its negative consequences and decrease length of stay [6].

The clinical assessment of ventilator-associated pneumonia VAP is usually based on the presence of fever (core temperature of more than $38.3 \mathrm{c}$ ), 
blood leukocytosis (more than 10,000 per $\mathrm{mm}^{3}$ ), or leukopenia (less than 4,000 per $\mathrm{mm}^{3}$ ), purulent tracheal secretions, and the presence of a new or persistent radiographic infiltrate [7].

CPIS is a score for calculated variables which was originally standardized by Pugin J. and his colleague, the score is proposed to combine the clinical signs recorded on the day of the clinical suspicion of VAP (including temperature, leukocytes, tracheal aspirate appearance and volume, chest $\mathrm{X}$-ray infiltrates, and $\mathrm{PaO}{ }_{2} / \mathrm{FiO}_{2}$ ratio) to the tracheal aspirate gram stain and culture which obtained later, into a CPIS as a diagnostic tool of pneumonia [8]

The CPIS has been most successfully used in guiding treatment decisions for patients with a low likelihood of VAP, for whom CPIS-guided therapy has resulted in lower costs and reduced development of antimicrobial resistance and in turn will decrease LOS [9].

The study objectives are early detection of cases of (VAP) using Clinical Pulmonary Infection Score (CPIS) and measurement of MV days and ICU length of stay.

\section{Material and Methods}

Setting and design: Operational research, quasiexperimental interventional study design. The study was conducted in the in Critical Care Department in the Faculty of Medicine, Cairo University from May 2012 to January 2014. One of the multidisciplinary major referral system for critical care patients, serving patients referred from the hospital and from outside.

Sample size and target population: All patients (convenient sample) admitted to the Critical Care Department and underwent intubation and mechanical ventilation according to inclusion and exclusion criteria were included during the period of the study.

\section{Inclusion criteria were:}

1-Patients admitted to the Critical Care Department and received mechanical ventilation.

2- Patients enter the study after agreement of the staff.

Exclusion criterion was: Patients diagnosed pneumonia before ventilation.

Data collection: Data were collected in 2 phases and we use the APACHE II scoring system for detection of clinical condition of MV patients within 24 hours from admission and predict the mortality rate of them, this score will affect the patient's outcome together with the associated comorbidities. Phase 1: Control group not using CPIS, each MV patient was visited in day 1 of MV, day 3 of MV and then every day till the day of extubation to collect clinical, laboratory, microbiological and radiological data. Phase 2: Intervention group using CPIS. Same as phase 1 and the staff was trying to use CPIS. At day 1 the CPIS was calculated based on first five variables which are temperature, blood leukocyte count, tracheal secretions, oxygenation, and character of pulmonary infiltrate in the X-ray. At day 3 of MV the CPIS was calculated based on all seven variables and took into consideration the progression of the infiltrate in chest X-ray and culture results of the tracheal aspirate, a score $>6$ at baseline or at $72 \mathrm{~h}$ is considered suggestive of pneumonia. If $<=6$ at 72 hours patient probably doesn't have pneumonia and antibiotics probably can be stopped.

Source of data: 1- Hospital Information System (HIS)-Medica pluse 4 software- from the Information Technology Department (IT). 2- Patient's files: The patient's medical records at bed site.

Pilot study was done and Statistical Package for Social Science (SPSS Version 17) was used for analysis.

\section{Ethical approval:}

The head of the Critical Care Department agreed the study protocol, the written approval was taken and patient confidentiality was protected by codifying the recorded information, making it identifiable. Approval of the study from the Scientific Research Committee of the department and that of the faculty was taken.

\section{Results}

The two groups were homogenous as there was no significant difference between both groups regarding age, clinical condition on admission which was assessed by APACHE II score.

In the current study the CPIS was lower in intervention group at the day 3 with significant difference $p=0.01$, the most common organism in the culture results in our study was the gram -ve organism Klebsiella (25\%) in control group versus gram +ve organism MRSA in intervention group $(17.5 \%)$. 
Table (1): Duration of Mechanical Ventilation (MV) and the ICU Length of Stay (LOS) in control group and intervention group

\begin{tabular}{lccc}
\hline Items & $\begin{array}{c}\text { Control Group } \\
\mathrm{n}=40\end{array}$ & $\begin{array}{c}\text { Intervention Group } \\
\mathrm{n}=40\end{array}$ & $\begin{array}{c}p \text { - } \\
\text { value }\end{array}$ \\
\hline MV days: & & & \\
Median & 9 & 8.5 & 0.81 \\
Minimum & 1 & 33 & \\
Maximum & 49 & & \\
ICU LOS: & & 11 & 0.06 \\
Median & 15 & 3 & \\
Minimum & 3 & 52 & \\
Maximum & 69 & & \\
\hline
\end{tabular}

The table shows insignificant difference in duration of MV and ICU LOS between both groups but it's lower in intervention group.

Table (2): Comparison between patients in intervention group who were followed by CPIS and who weren't followed by CPIS, regarding Mechanical Ventilation days (MV) days and ICU Length of Stay (LOS).

\begin{tabular}{lccc}
\hline Items & $\begin{array}{c}\text { Patients were } \\
\text { followed by } \\
\text { CPIS n=19 }\end{array}$ & $\begin{array}{c}\text { Patients weren't } \\
\text { followed by CPIS } \\
\mathrm{n}=21\end{array}$ & $\begin{array}{c}p \text { - } \\
\text { value }\end{array}$ \\
\hline MV days: & & & \\
Median & 7 & 2 & 0.04 \\
Minimum & 3 & 62 & \\
Maximum & 40 & & \\
ICU LOS: & & 13 & 0.02 \\
Median & 8 & 3 & \\
Minimum & 3 & 62 & \\
Maximum & 70 & & \\
\hline
\end{tabular}

The table shows that the MV days and ICU LOS were significantly lower in patients who were followed by CPIS.

Table (3): Comparison between control group and intervention group (who were followed by CPIS) regarding Mechanical Ventilation (MV) days and ICU Length of Stay (LOS).

\begin{tabular}{lccc}
\hline Items & $\begin{array}{c}\text { Control } \\
\text { Group } \\
\mathrm{n}=40\end{array}$ & $\begin{array}{c}\text { Intervention Group } \\
\text { (patients were followed } \\
\text { by CPIS) } \mathrm{n}=19\end{array}$ & $\begin{array}{c}p \text { - } \\
\text { value }\end{array}$ \\
\hline MV days: & & & \\
Median & 9 & 7 & 0.20 \\
Minimum & 1 & 3 & \\
Maximum & 49 & 40 & 0.01 \\
ICU LOS: & & & \\
Median & 15 & 8 & \\
Minimum & 3 & 70 & \\
Maximum & 69 & & \\
\hline
\end{tabular}

The table shows that the median of ICU days was significantly lower in patients in intervention group who were followed by CPIS.

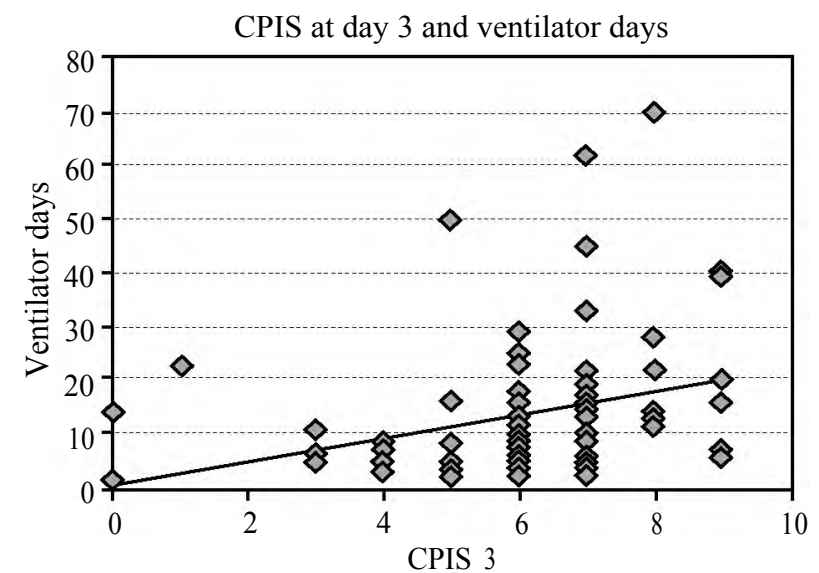

Fig. (1): Correlation between CPIS at day 3 and mechanical ventilation (MV) days in control group $n=40$ and intervention group $\mathrm{n}=40$.

The graph shows positive correlation. $r=0.3$ $p<0.01$.

\section{Discussion}

According to the microbiological culture, the prior use of antibiotics before VAP development is considered as a risk factor for HAIs. Moreover, a history of antibiotic use prior to the onset of Ventilator-Associated Pneumonia (VAP) increases the probability of infection with MultidrugResistant (MDR) pathogens which in turn increase the ventilator days [10].

The CPIS has been most successfully used in guiding treatment decisions for patients with VAP and resulted in lower costs and reduced development of antimicrobial resistance [11].

The current study was conducted in El-Kasr El-Aini Critical Care Department on MV cases and CPIS was used to study the changes of the score for early detection of VAP and to perceive the changes of the patient's response to antibiotics which reflected on the patient's outcome, hospitalization and the cost. According to the score when CPIS $\leq 6$ there was less possibility of VAP, therefore the staffs changed the prescription of the antibiotics for patients in intervention group according to their condition and take in consideration their associated comorbidities, which improve their condition and decrease the ventilator days and ICU LOS.

The most common organism in the culture results was the gram -ve organism Klebsiella in control group versus gram +ve organism MRSA in intervention group and this was agreed with 2 studies conducted in Critical Care Department in Alexandria Main University Hospital on VAP patients in which the gram -ve organism is more 
common in the culture Klebsiella pneumoniae and Pseudomonas aeruginosa followed by Staphylococcus aureas, the authors refer the significantly high rate of Gram negative bacilli in the study to the high incidence of prolonged hospital stay and the prolonged duration of mechanical ventilation that predisposes the patients to acquire infections from the multidrug-resistant pathogens [12,13]

One of the outcomes of proper management of VAP guided by CPIS was decrease the ICU LOS, in our study the median of MV days was apparently similar in both groups. The median of ICU LOS in intervention group was insignificantly lower than that in control group as present in (Table 1).

There was agreement of our results with study conducted in Surgical Intensive Care Unit, Zagazig University Hospitals in which the mean of ICU LOS of the VAP patients decreased from $35.3 \pm 21.7$ days in pre intervention group to $27.3 \pm 11.9$ days in post intervention group with no statistically significant difference between them $(p=0.64)$ [14]

The researcher of the study go throw intervention group and found that 19 cases $(47.5 \%)$ were followed by CPIS and 21 cases $(52.5 \%)$ weren't followed by CPIS due to the opinion of the ICU staff who were not familiar with using CPIS in MV patients and they recommend to start the antibiotics immediately to the patients once the ventilation started. More over 33\% of the cases who weren't followed by CPIS suspected to have MRSA due to history of MDR and they start antibiotics immediately and didn't follow the CPIS.

The median of MV days and ICU LOS were significantly higher in patients (who weren't followed by CPIS) than patients (who were followed by CPIS) as presented in (Table 2).

More over when comparing the control group (not using the CPIS) with those in intervention group (who were followed by CPIS), we found that the median of ICU LOS was significantly lower in patients (who were followed by CPIS) in intervention group as shown in (Table 3).

Similar results were found in other study in which the authors examine the relation of VAP with the duration and cost of hospital stay and they found that the mean of LOS in the ICUs was $15.7 \pm 9.1$ days in the VAP group and $4.9 \pm 4.9$ days in the control group, and $p<0.0001$. The mean of MV days lasted $12.8 \pm 7.9$ days in the VAP group and 3.6 \pm 4.2 days in the control group, and $p<0.0001$ [15].
Another study conducted at King Fahd hospital, Saudi Arabia showed that ventilator LOS and ICU LOS were significantly higher in the VAP group [16].

\section{Conclusion:}

The CPIS help the clinicians in early diagnosis of VAP and to observe the patient's response to treatment for better control of antibiotics use which decrease MV days and ICU LOS in intervention group.

\section{References}

1- APIC guide: Guide to the Elimination of VentilatorAssociated Pneumonia, 2009.

2- Centers for Disease Control and Prevention CDC, January: Device associated events, 2016.

3- RESTREPO M.I., ANZUETO A., ARROLIGA A.C., AFESSA B., ATKINSON M.J., HO N.J., SCHINNER R., BRACKEN R.L. and KOLLEF M.H.: Economic burden of ventilator-associated pneumonia based on total resource utilization. Infection Control Hospital Epidemiology, 31: 509-15, 2010.

4- HUANG K., TSENG C.H., et al.: March: An Early Predictor of the Outcome of Patients with Ventilator-associated Pneumonia, 2009.

5- MOHAMED K.: Compliance with VAP bundle implementation and its effectiveness on surgical and medical subpopulation in adult ICU. Egyptian Journal of Chest Diseases and Tuberculosis, 63: 9-14, 2014.

6- RELLO J.: Antibiotic stewardship in hospital-acquired pneumonia. Chest., 143: 1195-6, 2013.

7- JOSEPH N., SISTLA S., et al.: Ventilator associated pneumonia: A review. European Journal of Internal Medicine, 21: 360-8, 2010.

8- PUGIN J., AUCKENTHALER R., MILI N., JANSSENS J.P., LEW P.D. and SUTER P.M.: Diagnosis of ventilator associated pneumoniaby bacteriological analysis of bronchoscopic and non-bronchoscopic "blind" bronchoalveolar lavage fluid. American Review of Respiratory Disease, 143: 1121-9, 1991.

9- ZILBERBERG M. and SHORR A.: Ventilator-Associated Pneumonia: The Clinical Pulmonary Infection Score as a Surrogate for Diagnostics and Outcome. Clinical Pulmonary Infection Score Clinical Infectious Disease: 51 (Suppl 1), 2010.

10- GALANIS P. and VELDEKIS D.: Surveillance of DeviceAssociated Infection Rates and Mortality in 3 Greek Intensive Care Units. American Journal of Critical Care, 22: 3, 2013.

11- ZIMLICHMAN E., HENDERSON D., TAMIR O., FRANZ C., SONG P., YAMIN C., KEOHANE C., DENHAM $\mathrm{CH}$. and BATES D.: Health Care-Associated Infections A Meta-analysis of Costs and Financial Impact on the US Health Care. JAMA Internal Medicine, 173 (22): 203946, 2013.

12-ABU KHABAR H., ATTA S., BEDEWY KH., YOUSSEF A., MOUSTAFA A. and DECEMBER: Ventilator associ- 
ated pneumonia: The role of typical, atypical bacteria and fungi; comparison between endotracheal aspirate and broncoalveolar lavage. Egyptian Journal of Bronchology, 1 (1), 2007.

13- MOKHLESS N., EL-MOFTY M., HANAFI N., FAYED A. and ASSER S.: Atypical Bacteria in Ventilator Associated Pneumonia; an Egyptian University Hospital Experience. Medical Microbiology and Immunology, Critical Care Medicine, Faculty of Medicine University of Alexandria, Egypt. Journal of American Science, 6 (12), 2010.

14-ABO ELSEOUD A., ABOSEREA M., ABED EL RAZEK G.H. and HUSSEIN S.: An interventional study for reducing Ventilator Associated Pneumonia in Surgical
Intensive Care Unit, Zagazig University Hospitals. International Journal of Current Microbiology and Applied Sciences, 5 (2): 202-14, 2016.

15- KARAOGLAN H., YALCIN A., CENGIZ M., RAMAZANOGLU A.,OGUNC D., ERBAY R., YILMAZ M. and MAMIKOGLU L.: Cost analysis of ventilator-associated pneumonia in Turkish medical-surgical intensive care units. Le Infezioni in Medicina, n. 4: 248-55, 2010.

16- OTHMAN A.A. and ABDELAZIM M.S.: Ventilatorassociated pneumonia in adult Intensive Care Unit prevalence and complications. The Egyptian Journal of Critical Care Medicine. Volume 5, Issue 2, August, P 61-3, 2017.

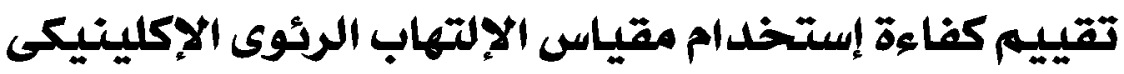

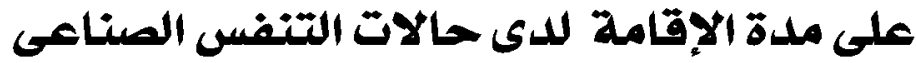

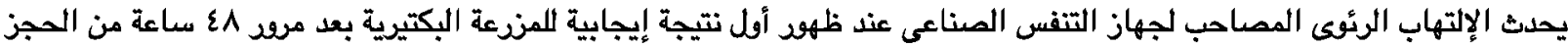

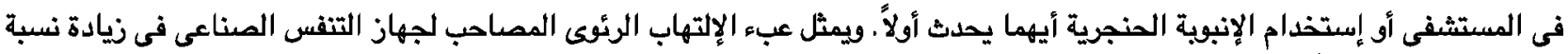 \\ المرض، التكلفة وأيضاً زيادة مدة إستخدام جهاز التفس الصناعى الإنى ومدة الإقامة فى وحدة العناية المركزة.

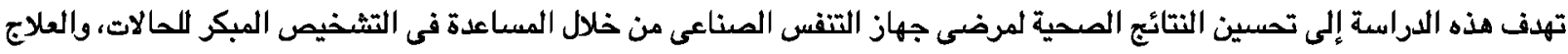

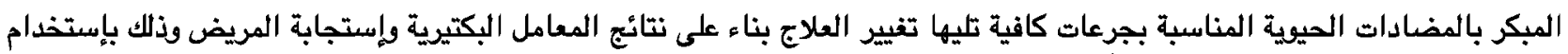 \\ مقياس الإلتهاب الرئوى الإكلينيكى. أيضاً تهدف الدراسة إلى تقلية الميل من مدة الإقامة على جهاز التنفس الصناعى ومدة الإقامة فى وحدة العناية \\ المركزة. \\ وجد أن متوبسط مدة الإقامة في وحدة العناية المركزة ومتوبط المدة المستخدمة لجهاز التنفس الصناعى للمرضى الذين تم متابعتهم

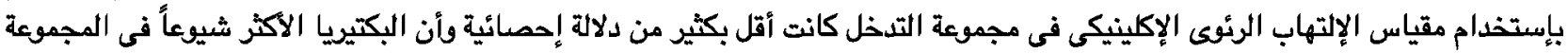 \\ الضابطة هي كليسيلات وفى مجموعة التذخل هي بكتيريا المكورات العنقودية المقاومة للميثيسلين. \\ نستنتج من هذه الدراسة أن مقياس الإلتهاب الرئوى الإكلينيكى يعتبر أداة لمراقبة حالة المرضى على جهاز التنفس الصناعى ودصد المهاء

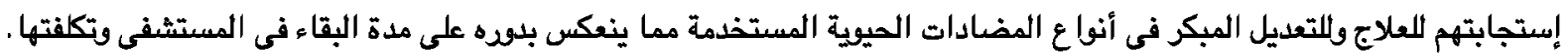

